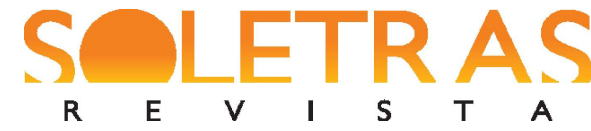

T A

\title{
A arquitetura construcional do que nem na Língua Portuguesa: mudanças construcionais e construcionalização
}

\author{
Caio Aguiar Vieira ${ }^{1}$ \\ Valéria Viana Sousa ${ }^{2}$
}

\begin{abstract}
Resumo: Neste trabalho, investigamos, sob o viés da Linguística Funcional Centrada no Uso (LFCU), as mudanças construcionais e a construcionalização do que nem utilizada na Língua Portuguesa como conector comparativo. Para tanto, a partir de uma análise quali-quantitativa, objetivamos, pelo prisma diacrônico, traçar a rota do pareamento de forma-função do que nem na Língua Portuguesa à luz dos tipos de contexto propostos por Diewald (2006) e, do ponto de vista sincrônico, analisamos, pela perspectiva construcional da mudança (BYBEE, 2010; TRAUGOTT; TROUSDALE, 2013; ROSÁRIO; OLIVEIRA, 2016; FURTADO DA CUNHA; BISPO; SILVA, 2018), o pareamento de forma-função do que nem e a sanção de novos nós na rede linguística com base nos corpora Popular e Culto de Vitória da Conquista - BA - Corpora PCVC e PPVC. Os resultados da pesquisa mostraram que um novo nó foi formado na Língua Portuguesa com configuração formal-funcional comparativa. Ademais, constatamos uma redução da composicionalidade do que nem, o aumento da esquematicidade e produtividade, evidenciando, assim, a expansão da classe hospedeira (HIMMELMANN, 2004), pois novos subesquemas foram acionados na rede, desempenhando a configuração formal-funcional de comparação, exemplificação e conformidade, aliado a um continuum crescente de (inter)subjetividade.
\end{abstract}

Palavras-chave: Que nem. Construcionalização. Linguística Funcional Centrada no Uso.

\section{Primeiras palavras}

Atualmente, o olhar cognitivista, principalmente no que concerne à concepção de que a língua(gem) é resultado de um pareamento de forma e função (GOLDBERG, 1995; CROFT, 2001), foi incorporado ao escopo teórico-metodológico dos estudos funcionalistas para análise da forma (propriedades fonológicas, morfológicas e sintáticas) e para a função (propriedades semânticas, pragmáticas e discursivas-funcionais). O diálogo entre essas duas teorias vem se tornando cada vez mais fecundo, pois, como afirma Oliveira (2018), a junção semântico-sintático assumida pela abordagem construcional de orientação cognitivista e

\footnotetext{
${ }^{1}$ Mestrando do Programa de Pós-Graduação em Linguística (PPGLin) da Universidade Estadual do Sudoeste da Bahia (UESB). Graduado em Letras pela Universidade Estadual do Sudoeste da Bahia (UESB). Integrante do Grupo de Pesquisa em Linguística Histórica e do Grupo de Pesquisa em Sociofuncionalismo - CNPq. Bolsista da Coordenação de Aperfeiçoamento de Pessoal de Nível Superior (CAPES).

${ }^{2}$ Doutora em Letras (área de concentração em Linguística e Língua Portuguesa) pela Universidade Federal da Paraíba (UFPB). Professora titular da Área de Linguística e Língua Portuguesa do Departamento de Estudos Linguísticos e Literários (DELL) da Universidade Estadual do Sudoeste da Bahia (UESB). Líder do Grupo de Pesquisa em Linguística Histórica e do Grupo de Pesquisa em Sociofuncionalismo - CNPq.
} 
conhecida, no Brasil, como Linguística Funcional Centrada no Uso (ROSÁRIO; OLIVEIRA, 2016) concebe a língua como um conjunto esquemático e interconectado de construções. Assim, a língua, nessa concepção, é vista como uma rede de construções que são definidas como pareamentos entre forma e função, cujo conteúdo, de natureza convencional, não é acessível pelas suas partes, mas sim holisticamente, tendo em vista que aspectos formais e funcionais são levados em consideração nessa proposta de análise linguística.

Neste artigo, a partir do viés teórico da Linguística Funcional Centrada no Uso (LFCU), temos o objetivo de investigar as mudanças construcionais e a construcionalização de forma-função da construção que nem, na Língua Portuguesa, produtiva em construções comparativas como ilustradas a seguir:

(1) INF: [...] acho uma grande idiotice realmente. Mas... tá... tá... vamo lá... gosto é gosto. Cada... gosto é que nem braço, tem gente que num tem [...] (Corpus PCVC. Período Contemporâneo. Século XXI)

(2) Vou me jogar nos teus braços [...] que nem Maria Bonita nos braços de Lampião (Trecho da música: Lucy Alves feat. Elba Ramalho - Xaxado no Chiado. Periodo Contemporâneo. Século $X X I)$.

Nesse sentido, a partir dessa observação inicial e amparados na perspectiva dos postulados da LFCU e em uma metodologia quanti-qualitativa, somos guiados pelas seguintes questões-problema: i) pelo âmbito diacrônico, como o pareamento forma-função do que nem se desenvolveu na Língua Portuguesa? ii) pelo âmbito sincrônico, como se constitui a rede construcional do que nem?; eiii) quais subesquemas são instanciados pelo que nem em sua rede construcional, ou seja, qual configuração formal-funcional do que nem no processo de expansão da host class?

A hipótese mais pertinente às questões-problema é a possibilidade do que nem ter passado pelos tipos de contexto, assim como proposto por Diewald (2006), a saber: Típico (faz viver tal vida, que nem d'el nem d'outrem nom ha[m] guarida), Atípico (por as ventuira, casou-se melhor que nem u a das outras), Crítico (e o seu açaframhe melhor que nem hu u outro) e Isolado (tem força que nem um touro), chegando à configuração formal- 
funcional comparativa. Assim, por meio de inferências sugeridas, (inter)subjetivação ${ }^{3}$, processos cognitivos de domínios gerais e mudanças construcionais, partimos do pressuposto de que o que nem é resultado de uma construcionalização gramatical que faz parte do domínio funcional $^{4}$ da conexão.

Ademais, hipotetizamos que houve uma redução da composicionalidade do que nem, aumento da esquematicidade e produtividade, evidenciando, assim, a expansão da classe hospedeira (HIMMELMANN, 2004), pois novos subsesquemas foram acionados na rede, desempenhando a configuração formal-funcional comparativa, de exemplificação e conformidade. Houve, portanto, uma expansão semântico-pragmática via mecanismo de neoanálise, aliada a um continuum crescente de (inter)subjetividade, deslocando de sentidos [+subjetivos] para sentidos [+intersubjetivos] que passam a identificar, cada vez mais, crenças e atitudes do falante acerca do que diz, com desenvolvimento de pareamentos mais abstratos, pragmáticos e interpessoais.

Este trabalho está estruturado em quatro seções, a saber. Na primeira, lançamos o olhar para a perspectiva construcionista da linguagem associado aos tipos de contexto; na segunda seção, mostramos os recursos metodológicos e os corpora utilizados; na terceira seção, que diz respeito às análises de dados, mapeamos, em perspectiva diacrônica, o uso prototípico da construção que nem, utilizando o Corpus Informatizado do Português Medieval e do Corpus do Português, aliados aos tipos de contexto. Ainda nessa parte do trabalho, estabelecemos, sincronicamente, uma rede hierárquica do que nem a partir dos corpora Popular e Culto de Vitória da Conquista, corpora PPVC e PCVC, a fim de identificar os três níveis de esquematicidade sistematizados por Traugott e Trousdale (2013), a saber: esquema, subesquema e microconstrução e os mecanismos cognitivos que instanciam novas construções. Na última seção, por fim, apresentamos as considerações finais, seguidas de nossas referências.

\footnotetext{
${ }^{3}$ Assim como Oliveira (2018), utilizamos o termo (inter)subjetividade, ao invés de subjetificação, pois defendemos que toda manifestação linguística acontece por meio de troca intersubjetiva.

${ }^{4} \mathrm{O}$ conceito de domínio funcional utilizado neste trabalho pode ser encontrado desde o Funcionalismo Clássico e diz respeito às "áreas linguísticas", concebidas, em uma perspectiva funcionalista, como "universais linguísticos" que não são passíveis de mudança e variação justamente por se tratar de áreas gerais e abstratas. Nessa concepção, os quantificadores, correlatores, subordinadores, coordenadores, focalizadores, conectivos, marcadores discursivos etc. fazem parte domínios funcionais distintos. Trata-se, como afirma Teixeira e Rosário (2016, p. 147), “[...] de 'universais psicológicos e socioculturais' presentes, senão em todas, em grande parte das línguas humanas".
} 


\section{Linguística Funcional Centrada no Uso: uma relação entre língua, uso e cognição}

$\mathrm{Na}$ abordagem funcional, o fenômeno linguístico é tomado como resultado da interação humana, aliada à atividade sociocultural, de uso e cognição. O papel dos usuários na construção gramatical é, sob essa perspectiva, um fator primordial, pois o método analítico se apoia em vários contextos de uso. A gramática, assim, não é vista como autônoma, mas como emergente, modificada e renovada a partir da necessidade intersubjetiva do falante.

Nesse sentido, uma proposta recente nos estudos funcionais reside no diálogo profícuo entre o Funcionalismo Norte-Americano (BYBEE, 2010) e o Cognitivismo (CROFT, 2001; GOLBERG, 1995). Essa junção teórica, denominada, no Brasil, como Linguística Funcional Centrada no Uso (ROSÁRIO; OLIVEIRA, 2016; FURTADO DA CUNHA; BISPO; SILVA, 2018), concebe a língua como um conjunto de construções, que apresentam dois polos que estão em relação simbólica (forma e função). Essas construções são entendidas como unidades simbólicas convencionais: (i) unidades porque alguns aspectos do signo são tão idiossincráticos ou tão frequentes que estão entrincheirados como um pareamento de formafunção na mente do falante; (ii) simbólicos pois são signos, tipicamente associações arbitrárias de forma e função; e (iii) convencionais porque são compartilhados entre grupos de falantes.

Sob essa perspectiva, a mudança linguística, de acordo com Traugott e Trousdale (2013), acontece sob dois aspectos: mudanças construcionais e construcionalização. O primeiro diz respeito à mudança que afeta, somente, a forma ou a função e não cria um nó na rede linguística. Essa fase é designada, portanto, como os micropassos da construcionalização, uma vez que as mudanças construcionais afetam somente um dos subcomponentes (formais ou funcionais) de uma construção já existente. Mesmo não criando um novo signo, esse tipo de mudança, aliada aos processos neoanálises e (inter)subjetivação, caracteriza-se como o gatilho para a formação de um novo signo na rede linguística. Já a construcionalização diz respeito à criação de um novo pareamento de forma-função na língua que envolve a necessidade comunicativa do falante, associada aos mecanismos de neoanálise e (inter)subjetividade. 
A análise, nessa perspectiva teórica, como afirmam Traugott e Trousdale (2013), deve se concentrar na detecção dos níveis mais abstratos e gerais que possibilitam a gênese e desenvolvimento da mudança linguística, pois a construcionalização, como resultado de mudanças construcionais, envolve mudanças no grau de esquematicidade, produtividade e composicionalidade elencados a seguir:

Esquematicidade: diz respeito às generalizações taxinômicas que evidenciam a abstratização de construções linguísticas na mente do falante em uma visão cognitivista nãomodular. Os falantes, nesse sentido, não têm conhecimento de somente um elemento linguístico específico, mas sim de esquemas mais abstratos e virtuais, conforme ilustram Traugott e Trousdale (2013, p. 17).

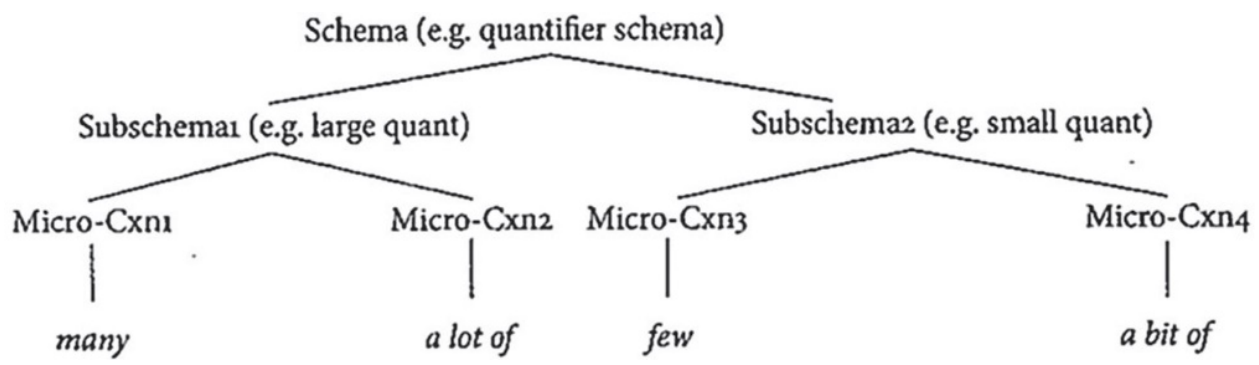

Figura 1 - Rede construcional dos quantificadores em Inglês - Fonte: Traugott e Trousdale (2013, p. 17)

Na Figura 1, é possível verificar o grau de esquematicidade dos quantificadores em Inglês e suas relações com outras construções. De um lado, temos a microconstrução (token ou uso efetivo) many e a lot of, que é, por sua vez, subesquema dos large quantifiers. Do outro lado, percebemos que as microconstruções few e a bit of instanciam um subesquema mais específico, o small quantifier, que, por fim, juntamente ao subesquema dos large quantifiers, sancionam o esquema ainda mais geral e abstrato: os quantificadores em Inglês.

Produtividade: relaciona-se à emergência de novos pareamentos de forma-função, ou seja, esse fator diz respeito à pontencialidade de esquemas mais gerais sancionarem construções menos esquemáticas. A noção de produtividade se relaciona, nos termos de Himmelmann (2004), com a expansão da host class (classe hospedeira), pois, após a construcionalização gramatical, novos pareamentos de forma-sentido são instanciados, aumentando, dessa forma, a produtividade. 


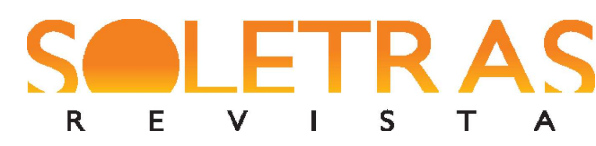

As sanções de novos nós, na rede, acontecem, sobretudo, devido às inferências sugeridas e intersubjetivação. De acordo com Traugott e Dasher (2005), a inferência sugerida, como um processo cognitivo, permite a ativação de construções que estão estreitamente relacionadas e, por meio de implicaturas conversacionais, novos nós são criados e os falantes convidam o seu interlocutor a interpretar e neoanalisar a nova construção de maneira particular, o que evidencia a sua necessidade comunicativa. A intersubjetivação, por sua vez, está estritamente ligada às inferências sugeridas, pois, com base na crença e na atitude do falante, há um processo de expansão semântico-pragmática. Assim, além de demonstrar as suas crenças (sentidos [+subjetivos]), a intersubjetividade ainda diz respeito à preocupação do falante com a imagem do interlocutor, agindo, dessa maneira, sobre ele, por meio da negociação de novos sentidos [+intersubjetivos] mediante a um continuum crescente de (inter)subjetividade.

Composicionalidade: diz respeito à relação de transparência entre a forma e a função. Temos construções mais composicionais, a exemplo do esquema Suj. V. Obj (João comeu o bolo), pois o significado do todo é recuperado pela soma das partes. Há construções, também, menos composicionais que se destacam pelo alto grau de entrincheiramento. Podemos exemplificar esses tipos de construções com expressões idiomáticas, como na frase: "Fui ao shopping, comprei roupas novas e vi minha amiga. Foi ótimo, pois matei dois coelhos numa cajadada só". Na expressão em destaque, muito comum no Português Brasileiro, o falante não indica que matou, de fato, dois coelhos no shopping, mas sim que ele resolveu duas situações de uma só vez. O significado do todo, portanto, não corresponde à soma das partes.

Nessa direção, quanto maior for a produtividade da construção, menor será sua composicionalidade, podendo gerar, inclusive, o encadeamento entre dois ou mais elementos, resultando em um chunk. De acordo com Bybee (2010), do plano de vista cognitivo, esse processo diz respeito à unidade organizacional da memória. Na esfera linguística, que faz parte dos processos cognitivos gerais, o chunking corresponde às sequências de palavras que são vistas como um único bloco de forma-função. Lôbo e Casseb-Galvão (2018), em um estudo com os marcadores discursivos, mostraram que houve o processo de chunking entre as construções [pois] + [não], instanciando um novo nó na rede dos marcadores discursivos no Português Brasileiro. Em nosso objeto, notamos que o mesmo fenômeno ocorre, pois, em sua 


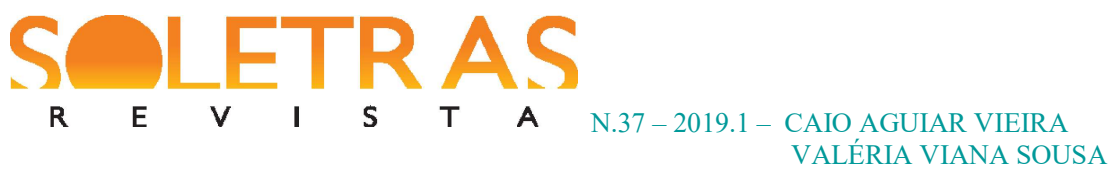

forma-função comparativa, o que nem é visto como um único bloco, fazendo parte da rede de conjunções comparativas devido aos contextos de uso.

\section{Tipos de contexto}

Um olhar sobre a importância do contexto para as mudanças construcionais rumo à construcionalização pode ser verificado no trabalho de Arena (2014) sobre a rota de construcionalização do daí que na Língua Portuguesa a partir dos tipos de contexto proposto por Diewald (2006). A construção “de aí se infere que" passou por mudanças construcionaischegando à construção "Não se infira daí que". A partir disso, o daí que se consolidou como conector lógico argumentativo, perdeu a sua composicionalidade e, por fim, gerou um novo nó na rede dos conectores. Mediante a esse exemplo, podemos verificar que o contexto é um fator crucial para a detecção de mudanças construcionais rumo à construcionalização.

A LFCU defende que, além da mudança do sentido, há, também, mudança na forma. Sob esse viés, o contexto tem duas dimensões, sendo elas: formais (propriedades sintáticas, morfológicas e fonológicas) e funcionais (propriedades semânticas, pragmáticas e discursivofuncionais), em que ambas “[...] dimensões motivam usos linguísticos e são motivadas por tais usos" (OLIVEIRA, 2015, p. 24).

Diewald (2006), baseada em uma perspectiva da gramaticalização, defende que o contexto deve ser analisado considerando um continuum escalar que integra aspectos semântico-sintáticos, morfológicos e estruturais, enfatizando, sobretudo, o papel das relações paradigmáticas entre construções num método diacrônico. Nessa perspectiva, o modelo adotado por Diewald (2006, p. 4), além do estágio típico ${ }^{5}$, considera três estágios cronologicamente ordenados para as funções gramaticais:

\footnotetext{
${ }^{5}$ O estágio que denominamos "típico" é considerado, na perspectiva de Heine (2002), como "uso normal”. 


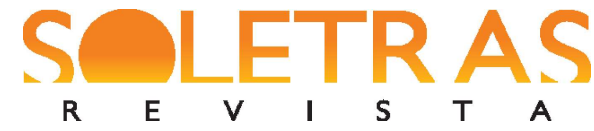

Estágio

I. Pré-condições de

gramaticalização

II. Gatilho para a gramaticalização

III. Reorganização e diferenciação

Quadro 1 - Tipos de contexto que propiciam a gramaticalização de construções. Fonte - Adaptado de Diewald (2006, p. 4).

Podemos observar, a partir do Quadro 1, os estágios que propiciam a gramaticalização por meio três tipos de contexto: Atípico, Crítico e Isolado. O primeiro estágio diz respeito às expansões inespecíficas da distribuição da unidade lexical para outros contextos em que, ainda, não tinham sido usadas. O sentido surge, dessa maneira, por meio das implicaturas conversacionais em que o“[...] significado é contextualmente e pragmaticamente acionado e não explicitamente codificado nos próprios itens linguísticos" (DIEWALD, 2006, p. 4, tradução nossa ${ }^{6}$ ).

No segundo estágio, por sua vez, é possível verificar um início do processo de gramaticalização. Há, assim, um acionamento real desse processo na estrutura e no significado da construção. Ele é denominado estágio crítico justamente pelo fato de conter ambiguidades que dificultam a interpretação da construção, haja vista que, devido às opacidades semânticas e estruturais, é possível perceber o gatilho para uma mudança linguística.

O último estágio é, então, a convencionalização, a perda de composicionalidade e o aumento da esquematicidade. Nessa fase, ocorre a implementação de um novo pareamento de forma-função, sem ser reversível ao estágio anterior. Ademais, é nesse momento, também, que acontece a expansão da classe hospedeira, pois uma construção já gramaticalizada gera polissemia devido aos mecanismos de neoanálise e intersubjetividade e novos types são formados a partir da construção matriz, não dependendo mais de implicaturas conversacionais.

\footnotetext{
${ }^{6}$ Versão original: [...] [the] meaning is contextually and pragmatically triggered and not explicitly encoded in the linguistic items themselves. 


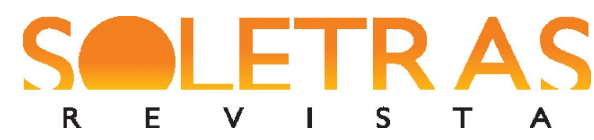

Notamos, dessa forma, que os tipos de contextos propostos por Diewald (2006) se relacionam, em certa medida, com a perspectiva da construcionalização gramatical, tendo que vista que, além da perda de elementos formais, a autora também mostra a importância contextual-pragmática para a consolidação da mudança linguística. A partir da concepção diacrônica de Diewald (2006), mostraremos, neste trabalho, como o que nem passou por mudanças construcionais até chegar ao contexto isolado com a perda da composicionalidade e o aumento da esquematicidade - que defendemos como o estágio da construcionalização gramatical. A seguir, veremos o delineamento metodológico no nosso trabalho.

\section{Procedimentos metodológicos}

A fim de investigar a rota de construcionalização do que nem, partimos do olhar pancrônico. Para tanto, dividimos os períodos analisados em três feixes temporais a partir das orientações de Mattos e Silva (2006), a saber: Período Arcaico, Período Moderno/Clássico e Período Contemporâneo.

O Período Arcaico envolve, segundo Mattos e Silva (2006), os séculos XIII ao XVI fase em que os primeiros documentos oficiais são escritos em Língua Portuguesa. Os dados para esse feixe temporal foram retirados do Corpus Informatizado do Português Medieval $\mathrm{CIPM}^{7}$.

O Período Moderno/Clássico diz respeito à época em que surgem as primeiras gramáticas responsáveis por descrever a morfologia e a sintaxe do Português, além de se manifestar as primeiras diferenças entre o Português falado na metrópole e nas colônias fazendo parte, segundo Mattos e Silva (2006), dos fins do século XVI ao XIX. Para os dados desse período, utilizamos o Corpus do Português (DAVIES; FERREIRA, 2006) que conta com dados falados e escritos em vários padrões discursivos. Devido à quantidade de ocorrências, recortamos, como recurso metodológico, somente o século XIX.

Por fim, o Período Contemporâneo, de acordo a autora, corresponde ao século XX e ao século XXI, fase marcada, principalmente, pela rapidez dos avanços tecnológicos, reestruturação lexical, além de representar o período em que as colônias que falavam

\footnotetext{
${ }^{7}$ O corpus pode ser conferido em: http://cipm.fcsh.unl.pt/ 
Português se constituíram na condição de nação. Levando-se em conta esse feixe temporal e o objeto pesquisado, o qual é muito utilizado em situações de interação dialogal, escolhemos os corpora do Português Popular e Culto da Comunidade de Vitória da Conquista (corpora PPVC e PCVC). Ambos corpora ${ }^{8}$ foram desenvolvidos pelo Grupo de Pesquisa em Linguística Histórica e em Sociofuncionalismo - CNPq, Grupo Janus, da Universidade Estadual do Sudoeste da Bahia - UESB, estratificados conforme os pressupostos teóricometodológicos LabovianosVariacionistas.

A partir dessa orientação metodológica, o trabalho se pautou em duas dimensões: diacrônico e sincrônico em uma análise quanti-qualitativa. Por meio da perspectiva diacrônica, i) verificamos os possíveis padrões sintáticos, discursivos e pragmáticos e as mudanças ocorridas desses padrões no decorrer da história; ii) analisamos as diferentes instanciações do que nem a partir dos tipos de contexto proposto por Diewald (2006); iii) averiguamos por quais mudanças construcionais o que nem sofreu até chegar ao seu estatuto de construcionalização gramatical, além de atestar o papel da inferência sugerida, (inter)subjetivação, neoanálise e dos processos cognitivos de domínio geral para consolidação de seu pareamento de forma-função; por fim, por se tratar de uma pesquisa centrada no uso, verificamos quantitativamente, a produtividade do que nem em cada feixe temporal.

Em uma perspectiva sincrônica, verificamos os fatores de esquematicidade, produtividade e composicionalidade e propomos uma rede hierárquica do que nem identificando os três níveis de esquematicidade sistematizados por Traugott e Trousdale (2013), a saber: esquema, subesquema e microconstrução e os mecanismos cognitivos que instanciam novas construções a partir de um continuum de (inter)subjetivação (TRAUGOTT; DASHER, 2005).

A análise empreendida neste trabalho, portanto, baseou-se em um método misto (CUNHA LACERDA, 2016). Por um lado, averiguamos o comportamento do nosso objeto em uma metodologia quantitativa - com levantamento da frequência de uso por tipos de contexto aliado aos feixes temporais. Por outro lado, exploramos uma análise qualitativa de exemplares sincrônicos, com a finalidade de destacar as especificidades dos usos atuais do que nem, tomando como amostra o vernáculo conquistense. Assim, veremos, na seção

\footnotetext{
${ }^{8}$ É valido ressaltar que os corpora Popular e Culto de Vitória da Conquista fazem parte do projeto "Estudos de fenômenos linguísticos na perspectiva (sócio) funcionalista, com base na descrição e análise da comunidade de fala de Vitória da Conquista", com cadastro no Certificado de Apresentação para Apreciação Ética (CAAE), número 34221214.9.0000.00552 e tendo como responsável a Prof. ${ }^{\mathrm{a}}$ Dr. ${ }^{\mathrm{a}}$ Valéria Viana Sousa.
} 


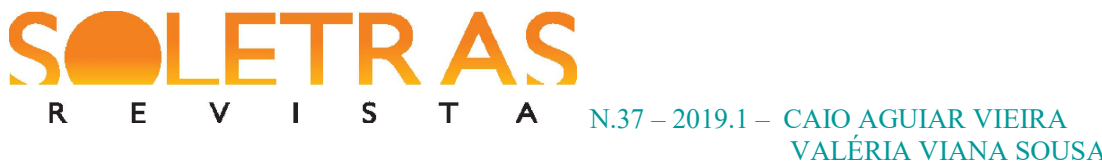

seguinte, como as inovações que emergem no fluxo da interação estão, de fato, se padronizando/regularizando na língua como construções empiricamente atestáveis.

\section{Análise de dados: rota de construcionalização do que nem}

Debruçamo-nos, como citado anteriormente, na perspectiva periodizante adotada por Mattos e Silva (2006) para a delimitação dos três feixes temporais do Português, a saber: Arcaico, Moderno/Clássico e Contemporâneo. Nesta parte do trabalho, fizemos, também, uma análise morfossintática, a fim de verificar o aspecto contextual e composicional que a construção em estudo se insere nos estágios Atípico, Crítico e Isolado proposto por Diewald (2006), além de propormos uma rede hierárquica a partir dos dados da comunidade de fala de Vitória da Conquista - BA. Na próxima subseção, veremos a rota de construcionalização do objeto em estudo a partir do contexto típico.

\section{Contexto Típico}

Baseamo-nos na hipótese de que foi, a partir de construções consecutivas, que o que nem se configurou como um pareamento forma-função mais abstrata, fazendo parte do domínio funcional da conexão. Ao analisar o Período Arcaico, verificamos a manifestação das partículas que e nem em uma estrutura de causa e consequência em Cantigas de Escárnio e Maldizer como no exemplo a seguir:

(3) [...] E pois el sa fazenda tam mal cata contra elas, que faz viver tal vida,que nem d'el nem d'outrem nom ha[m] guarida, eu nomlho tenho por bõa barata. (Cantigas de Escárnio e Maldizer - Séc. XIV)

Consideramos essas construções como típicas, haja vista que elas, em comparação aos exemplos (1) e (2), mostram diferenças tanto morfossintáticas quanto semânticas. No exemplo (3), é possível perceber uma estrutura de subordinação com um elemento intensificador tal e da partícula que na primeira oração,seguido de outro elemento determinante negativo nem+ 
[um], fazendo parte de uma estrutura subordinada consecutiva com alta transparência entre forma e função. Nos termos de Traugott e Trousdale (2013), há um nível elevado de composicionalidade, em razão do que atuar como uma conjunção (produtiva em orações subordinadas consecutivas) e o nem desempenhar a função de um elemento de negação.

Aliado ao fator de composicionalidade, notamos, ainda, um grau alto de esquematicidade, pois é maior a possibilidade de preenchimento de slots nesse tipo de oração. Defendemos, portanto, que construcionalização do que nem se deu a partir de uma estrutura consecutiva, considerada, neste trabalho, como o contexto típico.

Fried (2015) ressalta que a investigação pelo contexto primário de uma construção pode ser estabelecida por meio de muitos subconjuntos que apresentam características partilhadas. Nesse aspecto, Fried (2015) afirma que

[...] Semelhança familiar, frequentemente, está em jogo na captura de relacionamentos diacrônicos entre construções; nesses casos, somos confrontados com vários resíduos e desvios que podem deixar faltando partes da suposta hierarquia nos dados sincrônicos [...] A esse respeito, o elemento consolidado na rede não é uma construção raiz, mas um espaço funcional (ou conceptual) sobre o qual dadas construções podem ser mapeadas. (FRIED, 2015, p. 985, tradução nossa) $)^{9}$

Em nosso objeto de estudo, percebemos que tais aspectos podem ser verificados, de forma mais evidente no plano sintático, uma vez que há uma proximidade entre dois elementos [que] + [nem]. A partir da semelhança de família, essas duas partículas passaram por mudanças construcionais até chegar à construcionalização propriamente dita. Fundamentados nas considerações de Fried (2015) é que justificamos a hipótese de um padrão oracional consecutivo ter sido o contexto típico para a construcionalização do que nem.

\footnotetext{
${ }^{9}$ Versão original:“[...] Family resemblance is often at play in capturing diachronic relationships among constructions; in those cases we are confronted with various residues and drifts, which can leave pieces of the putative hierarchy missing in the synchronic data. [...]. In this respect, the unifying element in the network is not some root construction, but a functional (or conceptual) space onto which given constructions can be mapped".
} 


\section{Contexto Atípico}

É no Contexto Atípico que ocorrem as primeiras manifestações de mudanças. Nesse estágio, não é possível, ainda, verificar ambiguidades ou opacidades na forma e na função. No entanto, é possível perceber pressões contextuais aliadas às projeções metafóricas e metonímicas que denotam um grau mais alto de (inter)subjetividade do falante, destacado, principalmente, pela comparação, como exemplificado no trecho a seguir:

(4) E casou a filha maior com o duque de Cornoalha, e casou a outra com rei de Escotia, e nom curou da meor mas ela, por as ventuira, casou-se melhor que nem u a das outras, ca se pagou dela el rei de França, e filhou-a por molher. E depois, seu padre dela, em sa velhice, filharom-lhe seus genros a terra, e foi mal-andante; e houve a tornar a mercee d'el rei de França e de sa filha a meor, a que nom quis dar parte do reino. (CIPM. Narrativa de livro de linhagens. Período Arcaico. Séc. XIV).

No exemplo (4), é possível constatar uma estrutura comparativa, no entanto, ao fazer uma análise sintática da oração, verificamos que há, ainda, a presença de um item que intensifica a primeira oração e mantém a relação de consequência na segunda oração, conforme foi constatado no exemplo (3).

Embora seja possível notar uma relação de causa e consequência - característica das estruturas consecutivas - notamos que há, no excerto (4), a presença de uma comparação de superioridade, com a elipse na segunda oração. Além disso, o "por sua ventuira" contribui para fortalecer a intensificação da primeira oração. Essas implicaturas conversacionais demonstram que, mesmo havendo uma comparação com uma ancoragem mais (inter)subjetiva, estamos diante de uma estrutura de causa e consequência revelando, portanto, que a estrutura em questão passou por mudanças construcionais.

\section{Contexto Crítico}

De acordo com Diewald (2006, p. 20, tradução nossa ${ }^{10}$ ), o Contexto Crítico é marcado por muitas ambiguidades e opacidades estruturais e semânticas, diferindo-se da fase

\footnotetext{
${ }^{10}$ Versão original: [...] a highly ambiguous structure, [and] [...] allows several options for its interpretation, among them the new grammaticalized meaning.
} 
atípica. Isso ocorre porque, no contexto crítico, a estrutura é “[...] altamente ambígua [e] [...] permite várias opções para sua interpretação, dentre elas um novo significado gramaticalizado [...]". Veremos, a seguir, como, no exemplo (5), é ilustrado esse contexto:

(5) Tolledo he muy boa cidade e de muy grande prazer e mui forte e muy defesa, ca, pero que a cercarom muytos poderes per muytas vezes, sempre se teve muy ben. E sempre foy muy proveytosa a seus lavradores e sempre foy de boa conteença. E he de boa sementeyra e he terra de boo aar e o pam dura hy muyto tempo que se no da na, ca podem muy bem te $\sim$ e $r$ o trigo nas covas per [dez] annos que nu ca seera muy da nado; e por esto se tiinha quando a guerreava . E o seu açafram he melhor que nem hu u outro de todollos d'Espanha, assy e tintura como e coor. (CIPM. Crónica Geral de Espanha. Periodo Arcaico. Século XIV).

No exceto (5), notamos que o locutor ${ }^{11}$ busca, por meio de adjetivos, repetições e expressões metafóricas, exaltar as qualidades de Tolledo e, ao final, com o objetivo de mostrar que o seu açafrão da cidade é o melhor que outros da Espanha, utiliza a comparação. Esse recurso demonstra o posicionamento avaliativo e (inter)subjetivo do locutor acerca da cidade. Do plano de vista formal, notamos uma estrutura comparativa, haja vista esse tipo de estrutura, pela Tradição Gramatical, a exemplo de Bechara (2009), é marcada pelo traço de dependência de um antecedente de natureza quantificadora ou qualificadora e mantém relação direta com o núcleo verbal da oração junto com seu antecedente.

Sobre o assunto, Bechara (2009) evidencia a relação das orações tanto consecutivas quanto comparativas com as estruturas adverbiais, observando que elas dependem de um elemento intensificador adjetival/adverbial na primeira oração. Dessa forma, por mais que haja uma comparação, do plano de vista sintático, há a presença do elemento subordinativo quee do elemento de negação nem, demonstrando, assim, como no Estágio Atípico, mudanças construcionais. À vista disso, embora a função exercida seja de comparação, ainda não é possível analisar o que nem como um único bloco de forma-função. Fundamentados nessa constatação, defendemos que esse contexto tenha sido propício para a instanciação de um novo nó na Língua Portuguesa, uma vez que o falante, devido às inferências sugeridas, explora as implicaturas da língua fazendo com que o seu interlocutor interprete uma nova construção.

\footnotetext{
${ }^{11}$ Neste trabalho, utilizamos o termo "locutor" e não "falante" devido ao fato de estarmos trabalhando com dados extraídos de corpus na modalidade escrita e não com dados orais.
} 
Nesse sentido, como afirma Cunha Lacerda e Oliveira (2015, p. 54), a (inter)subjetivação possibilita “[...] a codificação linguística daquilo que emergiu na interação [...]”, e, por isso, sustentamos a hipótese que, mediante ao contexto crítico, o locutor/falante fez uma neoanálise dos significados resultando um novo pareamento de forma-função na Língua Portuguesa, propiciando, consequentemente, o Contexto Isolado do que nem.

\section{Contexto Isolado}

No Contexto Isolado, não há mais ambiguidades na interpretação da estrutura e do sentido. Os exemplos (6) e (7), a seguir, ilustram o estágio em que o que nem é visto como um novo pareamento de forma-função:

(6) Não pôde porém sustentar estro tão alto e descahiu logo em legitimo vôo icario para o ridiculo: - Mas de tal consumição Olha bem, cruel Gêgéca, Vou ficando magro e secco que nem feia perereca! - E assim por diante, a não acabar mais, tudo muito chupado, cheio de si! (C.P. Ao entardecer - Afonso Taunay. Período Moderno/Clássico. Século XIX).

(7) Soltem-me. Quero ir-me embora - respondeu Lourenço, rugindo de raiva, e revolvendo-se entre os braços dos matutos a quem Francisco o tinha abandonado logo que reconheceu nele os anos infantis que na escuridão o fizeram ter por forte e varonil atleta. Que menino! disse Francisco, correndo-o com a vista de cima a baixo. Tem força que nem um touro. Assim é que eu gosto de ver um cabrinha bom. (CP. O Matuto - Franklin Távora. Periodo Moderno/Clássico. Século XIX).

Em (6) e (7), as partículas que e nem estão integradas, operando com forma-função de comparação nos dados do Período Moderno/Clássico. Além disso, constatamos que houve, nesses contextos, uma redistribuição categorial, aliada à perda de propriedades sintáticosemânticas, caracterizando como a fase de isolamento. O que e o nem, nos exemplos (6) e (7),do plano de vista formal-funcional, apresentam-se como bloco único, fazendo parte das conjunções usadas para construções comparativas. Com base nos dados do Português Moderno/Clássico, podemos afirmar que o que nem se tornou um novo signo na língua, havendo, a partir da neoanálise, uma 


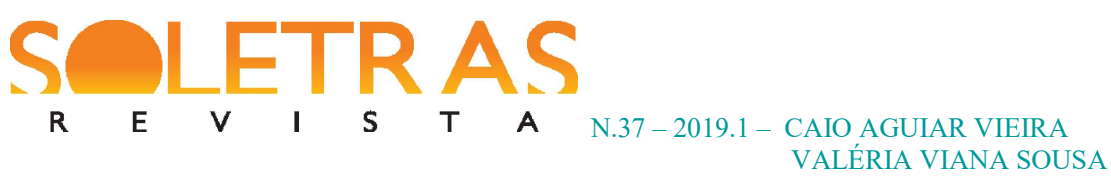

[...] nova sintaxe ou morfologia e novo significado codificado na rede linguística de uma população de falantes [...] acompanhado por mudanças no grau de esquematicidade, produtividade e composicionalidade. A construção de esquemas sempre resulta de uma sucessão de micro-etapas e, portanto, é gradual. [...] Minimamente, a construcionalização envolve a neoanálise da forma morfossintática e o significado semântico/pragmático. (TRAUGOTT; TROUSDALE, 2013, p. 22, tradução nossa ${ }^{12}$ ).

Sob esse viés, além da neoanálise, constatamos o chunking dos elementos [que + nem]. Defendemos, portanto, que o que nem, devido aos fatores contextuais, associados a processos cognitivos de domínio geral e de uso, é resultado de uma construcionalização gramatical. Nesse pareamento de forma-função, não há mais composicionalidade entre as duas partículas, pois não é possível preencher o slot de negação com outro elemento (a exemplo do não, nunca etc.). O quadro 2 demonstra as mudanças construcionais sofridas pela construção em estudo até chegar ao seu estatuto de construcionalização gramatical:

\begin{tabular}{|c|c|c|c|c|c|c|c|}
\hline & Oração I & Intensificador & SN. & Conjunção & $\begin{array}{c}\text { Elemento } \\
\text { de } \\
\text { negação }\end{array}$ & UM & $\begin{array}{c}\text { Oração } \\
\text { II }\end{array}$ \\
\hline $\begin{array}{c}\text { Contexto } \\
\text { Típico }\end{array}$ & {$[\ldots]$ faz viver } & Tal & vida & [que] & [nem] & $\varnothing$ & $\begin{array}{c}\text { d'el nem } \\
{[\ldots]}\end{array}$ \\
\hline $\begin{array}{c}\text { Contexto } \\
\text { Atípico }\end{array}$ & [...]casou-se & Melhor & $\varnothing$ & [que] & [nem] & Uma & Outra Ø \\
\hline $\begin{array}{c}\text { Contexto } \\
\text { Crítico }\end{array}$ & [...] açafrão he & Melhor & $\varnothing$ & [que] & [nem] & $\mathrm{Um}$ & $\begin{array}{c}\text { Outro } \\
{[\ldots]}\end{array}$ \\
\hline $\begin{array}{c}\text { Contexto } \\
\text { Isolado }\end{array}$ & $\begin{array}{c}\text { [...] Vou } \\
\text { ficando magro } \\
\text { e seco }\end{array}$ & $\varnothing$ & $\varnothing$ & [que nem] & $\varnothing$ & $\varnothing$ & $\begin{array}{c}\text { Feia } \\
\text { perereca }\end{array}$ \\
\hline
\end{tabular}

Quadro 2 -Tipos de contexto do envolvidos na construcionalização do que nem.

\footnotetext{
${ }^{12}$ Versão original: [...] new syntax or morphology and new coded meaning, in the linguistic network of a population of speakers. It is accompanied by changes in degree of schematicity, productivity, and compositionality. The constructionalization of schemas always results from a succession of micro-steps and is therefore gradual [...] Minimally, constructionalization involves neoanalysis of morphosyntactic form and semantic/pragmatic meaning.
} 
Para esta pesquisa, foram coletados, considerando os 4 (quatro) tipos de contexto, 1084 (mil e oitenta e quatro) construtos/tokens nos quatro de tipos de contexto. Salientamos que os exemplos e a análise construcional do Estágio Isolado, no Período Contemporâneo, serão apresentados na próxima subseção. No entanto, trazemos a distribuição quantitativa de todos os contextos analisados neste estudo na Tabela 1 a seguir:

\begin{tabular}{lccccccc}
\hline TIPOS DE & \multicolumn{7}{c}{ DADOS } \\
\cline { 2 - 8 } CONTEXTO & \multicolumn{1}{c}{ PERÍODO } & \multicolumn{2}{c}{ PERÍODO } & \multicolumn{2}{c}{ PERÍODO } & TOTAL \\
& ARCAICO & MODERNO & CONTEM. & \\
TÍPICO & Tokens & $\%$ & Tokens & $\%$ & Tokens & $\%$ & Tokens \\
\hline ATÍPICO & 52 & $74,3 \%$ & 788 & $84,3 \%$ & 10 & $12,6 \%$ & 850 \\
CRÍTICO & 12 & $17,1 \%$ & - & - & - & - & 12 \\
ISOLADO & 6 & $8,6 \%$ & - & - & - & - & 6 \\
TOTAL & - & - & 147 & $15,7 \%$ & 69 & $87,4 \%$ & 216 \\
\hline
\end{tabular}

Tabela 1 - Distribuição de ocorrências do que nem.

A partir dos dados quantitativos, realizando a leitura vertical por período da Língua Portuguesa, como propõe Mattos e Silva (2006) e, em seguida, observando os contextos horizontalmente, podemos afirmar que:

i) os construtos/tokens empiricamente atestados do que nem no Contexto Típico foram bastante recorrentes no Período Medieval e, ainda, no Período Moderno, mas, no Período Contemporâneo, apoiado nos dados da comunidade de fala de Vitória da Conquista - BA, houve uma redução significativa desse tipo de realização;

ii) com relação ao Contexto Atípico, houve, apenas, construtos/tokens no Período Arcaico representados por $17,1 \%$ dos dados;

iii) ratificando o que foi proposto por Diewald (2006), observamos que o Contexto Crítico foi o menos produtivo, pois, em nossos dados, esse tipo de Contexto se limitou a 8,6\%, não aparecendo em outros feixes temporais. Dessa forma, é possível "[...] notar que, em contraste com os outros tipos de contexto, a existência do contexto crítico é restrita a um período de 
tempo bastante limitado na história e não existe antes ou após esse período." (DIEWALD, 2006, p. 20, tradução nossa $)^{13}$;

iv) o Contexto Isolado, por sua vez, no Período Medieval, não foi, em nossos corpora, identificado realização alguma, ao passo que, no Período Moderno, a sua realização esteve presente $(15,7 \%)$ e, no Período Contemporâneo, a sua realização foi bastante produtiva equivalendo $87,4 \%$.

Como a noção de produtividade está relacionada com a gradiência dos padrões esquemáticos (BYBEE, 2010; TRAUGOTT; TROUSDALE, 2013), inferimos que, a partir da construcionalização do que nem como comparativo, já assinalado nos exemplos (6) e (7), outros pareamentos de forma-função foram instanciados em sua rede construcional. Veremos, então, no Período Contemporâneo, baseados nos Corpora PPVC e PCVC, como o que nem instancia novos nós.

\section{Proposta de rede taxinômica para o que nem}

No Contexto Isolado, conforme discutido na seção anterior, percebemos que as partículas que e nem apresentam um alto nível de entrincheiramento sintático-semântico, perdendo, nos termos de Traugott e Trousdale (2013), a composicionalidade.

Notamos que, além da forma-função comparativa visto anteriormente no exemplo (6) e (7) houve, também, um aumento da produtividade, pois o que nem instancia mais dois novos nós em sua rede construcional, a saber: exemplificação e conformidade - demonstrando que houve a expansão da classe hospedeira (HIMMELMANN, 2004) e da esquematicidade.

Levando em consideração que, na LFCU, a língua se constitui como uma rede de nós que se interconectam por meio de links no nível da microconstrução (token empiricamente atestado), subesquema e esquemas mais virtual e abstrato, faremos, nesta parte do trabalho, uma análise qualitativa, a fim de verificar os graus de esquematicidade do que nem no Português Contemporâneo. Apresentaremos, a seguir, o esquema, os subesquemas e as microconstruções licenciadas pelo objeto em estudo:

\footnotetext{
${ }^{13}$ Versão original: "[...] note that, in contrast to the other context types, the existence of the critical context is restricted to a fairly narrow time span in history and does not exist before or after that critical period".
} 


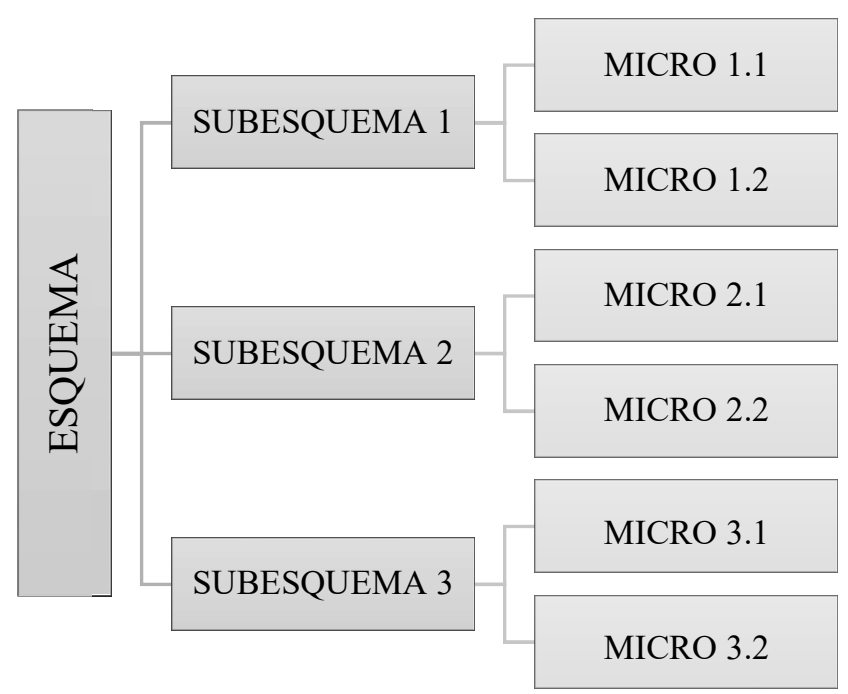

Figura 2 - Rede virtual do que nem no Português.

\section{Esquema}

A construção que nem faz parte de um esquema geral $\left\{\left[\mathrm{O}_{[\mathrm{V} 1]}\right]+\right.$ QUE NEM $+[\mathrm{X}]+$ $\left.\left[\mathrm{V}_{\mathrm{dic}}\right]\right\}$ que encabeça construções comparativas $>$ exemplificativas $>$ conformativas. Notamos que, nessa hierarquia construcional, o esquema se configura como parcialmente esquemático (ou parcialmente especificado) com a possibilidade de: i) oração $\left[\mathrm{OV}_{[\mathrm{V} 1]}\right]$ com o núcleo verbal, podendo ser distinto da oração posposta ao que nem; ii) Sintagma Nominal [SN] ou oração [X] que, nas construções de conformidade, podem ser encabeçadas por verbo distinto da primeira oração; e iii) um verbo dicendi (a exemplo de falei, disse etc) com uma parte substantiva (lexicalmente especificada) representada pelo chunk \{QUE NEM\}.

$\mathrm{Na}$ próxima subseção, analisamos o comportamento do nosso objeto de estudo na parte intermediária da rede taxinômica.

\section{Subesquema 1}

O subesquema 1 tem, como forma, o esquema $\{[\mathrm{O}+\mathrm{QUE}$ NEM $+\mathrm{X}]\}$ e, como função, o aspecto comparativo. Esse subesquema instancia duas microconstruções, sendo a 


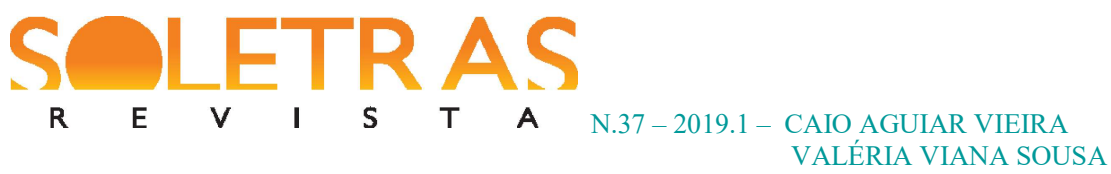

primeira representada pela forma-função $\{[\mathrm{O}+\mathrm{QUE} \mathrm{NEM}+\mathrm{O}]\}^{\text {comp }}$, preenchida por uma oração correlacionada com o que nem. Há, nesse tipo de construção, uma maior dependência das orações, pois, para comparar um evento, é necessário que haja uma correlação com a segunda oração como no exemplo (8):

(8) INF: não tinha água nenhuma, só tinha mesmo era no poço escuro então \{ININT\} [vendê aqueles balde de água que nem vendia leite] a... a... a mesma coisa os balde de água lá, né?! (Corpus PPVC. Periodo Contemporâneo. Século. XXI).

O falante em (8), na primeira oração, explica que, na sua época, não havia água, sendo necessário comprá-la. Para facilitar a interlocução, o informante compara, na segunda oração, os baldes de água vendidos com baldes de leite, revelando, assim, uma dependência maior com a oração anterior. A segunda microconstrução, por sua vez, instanciada no subesquema 1 , tem menor dependência oracional, mas se mantém correlacionado com um sintagma nominal que, do ponto de vista formal-funcional, pode ser representado por $\{[\mathrm{O}+\mathrm{QUE} N E M+$ $\mathrm{SN}]\}^{\mathrm{comp}}$.

(9) INF: [...] Isso foi no sábado, quando foi no domingo, já tive que levar pro hospital, [a mão já tava dessa altura preta que nem um carvão], o braço todin' inchou cum coisa que meteu num pau de vara de fogo assim, inchou todo, todo, todo e deu aquelas bolha de fogo [...] (Corpus PPVC. Séc. XXI. Periodo Contemporâneo).

No exceto (9), verificamos que o falante, ao tentar explicar para seu interlocutor a gravidade da inflamação do braço, compara o seu aspecto ao de um carvão, pelo fato do aspecto roxo que o inchaço causou. Além disso, constatamos que, nos exemplos (8) e (9), há uma ancoragem [+(inter)subjetiva], pois o falante, com uma maior necessidade de expressividade aliada à preocupação com o self do seu interlocutor, compara dois eventos para facilitar a argumentação.

\section{Subesquema 2}

O subesquema 2 tem como padrão construcional formal o esquema $\{[\mathrm{O}]+[\mathrm{QUE}$ $\mathrm{NEM}+\mathrm{X}]$ \} e a função exemplificativa. Esse subesquema é sancionado, também, por duas 


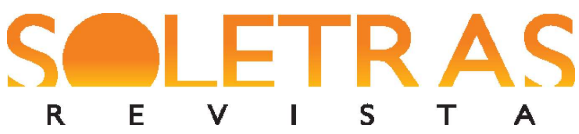

N.37 - 2019.1 - CAIO AGUIAR VIEIRA

VALÉRIA VIANA SOUSA

microconstruções: i) correlacional, representada por $\{[\mathrm{O}]+[\mathrm{QUE} N E M+\mathrm{O}]\}^{\text {exemp }}$; ii) e pela validação da informação de modo individualizado com o pareamento $\{[Q \mathrm{QUE} N E M+$ $\mathrm{SN}]\}^{\text {exemp }}$. Vejamos, a seguir, nos exemplos (10) e (11):

(10) INF: [agora eu vejo professô ensina aí...] [que nem quando eu estudava mesmo...] na minha sala tinha sessenta... setenta aluno [com] um professô só tomá conta ali daquilo tudo dá aula pra aqueles aluno tudo e quando ele vê no final do mês, ele olha o salário dele aquela mixaria né, aquele pôquin' (Corpus PPVC. Periodo Contemporâneo. Século. $X X I)$.

(11) INF: Mudou, tá muito quente. Muito quente mermo. Num sei como nesses lugares vizinhos... [que nem Jequié] tá aumentano viu. Anagé mermo a barragem tá bem baixa, ININT esses tempo aí atrás. (Corpus PCVC. Periodo Contemporâneo. Século. XXI).

No fragmento (10), o falante conta para seu interlocutor sobre as dificuldades pelas quais os professores passam. Como estratégia argumentativa, o informante utiliza um exemplo da época em que ele estudava para ratificar sua alegação. Há, nesse excerto, uma maior dependência do que nem com a oração seguinte e não com a que a antecede. É, então, nesse sentido, que, do ponto de vista formal, ela se distingue das comparativas instanciadas pelas microconstruções do subesquema 1. Já no exemplo (11), com a finalidade, também, de exemplificar, o falante intercala o QUE + SN de modo individualizado. Esse slot, portanto, pode ser preenchido por SNs a exemplo de: que nem ele, que nem Salvador, que nem Maria, evidenciando a marca (inter)subjetiva do falante.

\section{Subesquema 3}

Esse pareamento de classe intermediária tem a configuração $\left\{\left[\mathrm{O}_{\mathrm{V} 1}\right]+\right.$ QUE NEM + $\left.\left.[\mathrm{SN}]+\left[\mathrm{V}_{\mathrm{dic}}\right]+\mathrm{O}_{\mathrm{V} 2}\right]\right\}^{\text {conf }}$ que sanciona, também, duas microconstruções. Realiza isso por meio de formas e funções conformativas. Nos exemplos (12) e (13), veremos como se manifesta esse pareamento:

(12) DOC: O que o senhor acha do prefeito?

INF: prefeit' foi bom, esses tempo de mandato dele... os primeiros mandato ele foi um prefeito bom, já ness... segundo... nesse último agora ele num tá bom não?

DOC: E... por que? 


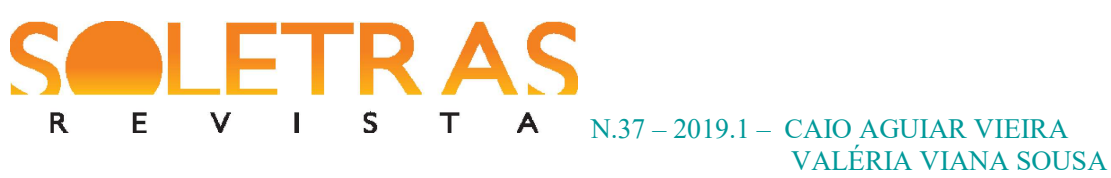

INF: Poque num [tafazenas coisa que nem ele deveria]. Nesses cant de rua aí só... só tem esgoto a céu aberto, e água corren na rua e o povo quexane nada, ele num faz nada. (Corpus PPVC. Período Contemporâneo. Século. XXI).

(13) DOC: É assim... os brinquedos de antes não eram tão... modernos como os de agora... INF: Não, não eram.

DOC: ...que eu tava tentando dizer.

INF: Não era. Era diferente, né, que nem eu falei [...] (Corpus PPVC. Período Contemporâneo. Século. XXI).

No trecho (12), o documentador pergunta sobre a administração do prefeito para o informante. $\mathrm{O}$ entrevistado, por sua vez, afirma que, no segundo mandato, o prefeito não foi tão bom quanto no primeiro. Ao ser questionado do porquê dessa afirmação, o informante responde que o prefeito não fez aquilo que um gestor deveria fazer. Temos, à vista disso, numa perspectiva formal, a correlação da construção que nem,em duas orações com núcleos verbais distintos, que podem ser representados pelo esquema $\left\{\left[\mathrm{O}_{\mathrm{V} 1}+\right.\right.$ QUE NEM + $\left.\left.\mathrm{O}_{\mathrm{V} 2}\right]\right\}^{\text {confor }}$. A partir do exemplo (12), vemos que a primeira oração é encabeçada pelo verbo fazer e a segunda, por seu turno, é gerida pelo verbo deveria. Ressaltamos que, mesmo se o informante utilizasse uma locução verbal na segunda oração, retomando o verbo da primeira (deveria fazer), a configuração formal seria dessemelhante do subesquema 1, comprovando, portanto, o emparelhamento de forma-função distinto.

O exemplo (13) é marcado pelo seu caráter formal-funcional $\{[\mathrm{QUE} N E M+[\mathrm{SN}]+$ $\left.\left.\mathrm{V}_{\mathrm{dic}}\right]\right\}^{\text {confor }}$. Nessa microconstrução, podemos observar a utilização do chunk que nem, um sintagma nominal (eu) e um verbo de dicendi (falei). É possível, ainda, que o SN não apareça, a exemplo de que nem disse, que nem comentei. Notamos, nesse pareamento, uma preocupação do falante em retomar o que foi dito no início da entrevista, mostrando um grau maior de (inter)subjetividade, pois, além de ser empregada com uma função interacional, essa construção resgata a informação para confirmar seu ponto vista e suas crenças acerca do que foi dito anteriormente.

Por fim, com o objetivo de demonstrar como os padrões construcionais se organizam na rede cognitiva do falante, propomos a seguinte rede taxinômica do que nem no domínio funcional da conexão: 


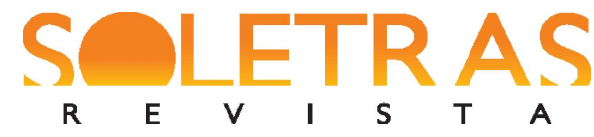

N.37 - 2019.1 - CAIO AGUIAR VIEIRA

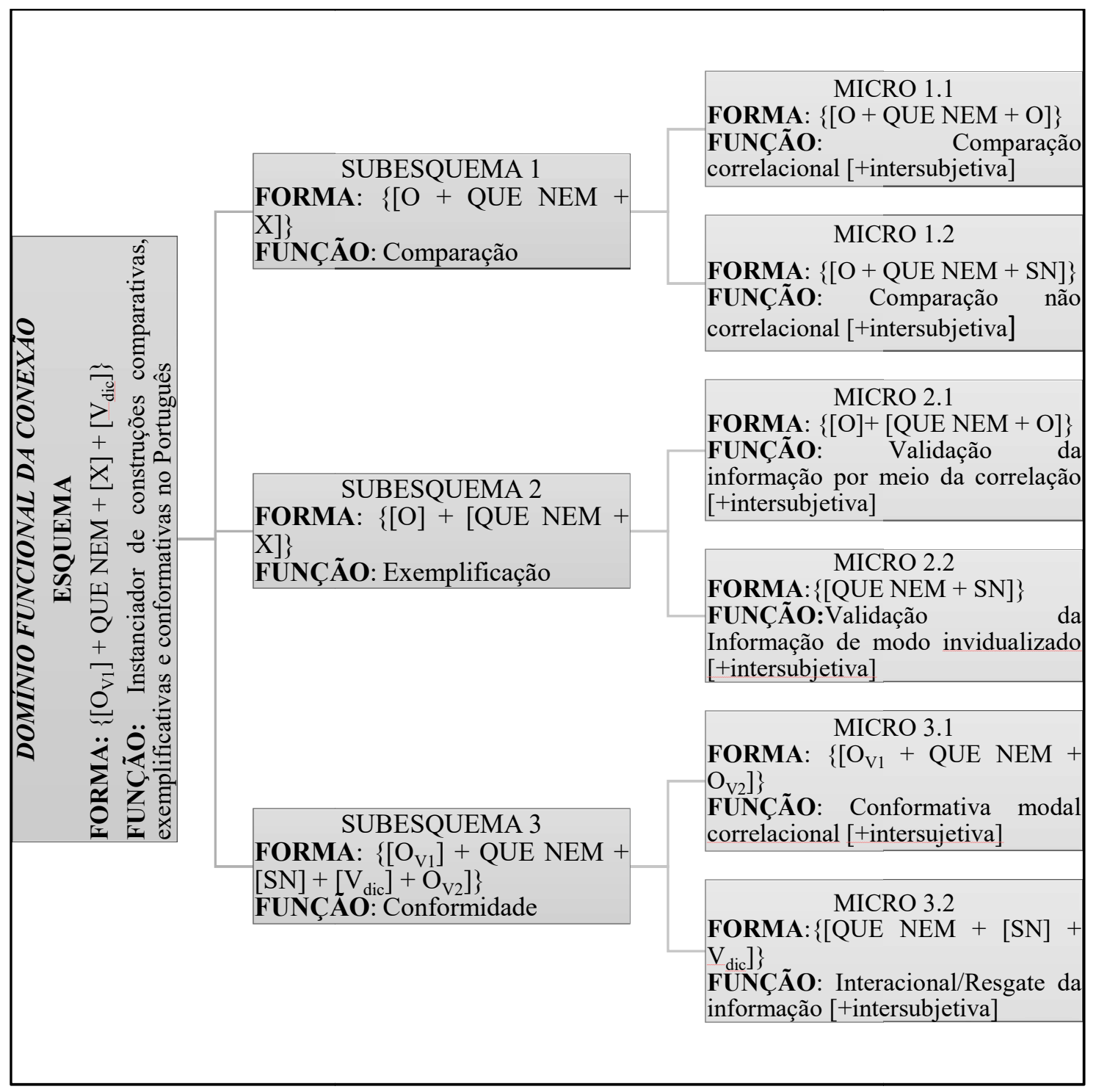

Figura 3 - Proposta de rede construcional do quenem em perspectiva sincrônica.

\section{Considerações finais}

A partir desta pesquisa, podemos afirmar que nossas hipóteses foram confirmadas, pois constatamos que um novo nó foi sancionado na Língua Portuguesa originada de uma estrutura de causa-consequência em um contexto que consideramos típico. Além disso, mediante à perspectiva da LFCU, podemos afirmar, tomando como amostra os dados da comunidade de fala de Vitória da Conquista, que houve: i) uma redução da composicionada de e a formação do chunking que + nem; ii) um processo de expansão semântico-pragmático, 


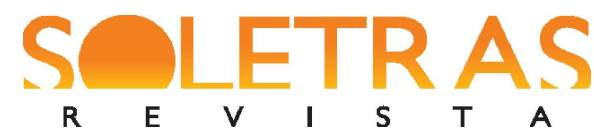

N.37 - 2019.1 - CAIO AGUIAR VIEIRA

VALÉRIA VIANA SOUSA

via mecanismo de neoanálise com o desenvolvimento de funções mais abstratas, pragmáticas e interpessoais; iii) um continuum crescente de (inter)subjetividade com pareamentos de forma-função que passam de sentidos [+subjetivos], identificando as crenças e atitudes do falante acerca do que diz e chegando, cada vez mais, a sentidos [+intersubjetivos] assim como defendido por Traugott e Dasher (2005); iv) um aumento da esquematicidade e produtividade, evidenciando a expansão da classe hospedeira.

Por fim, esta pesquisa faz parte dos estudos realizados pelo Grupo de Pesquisa em Linguística Histórica e em Sociofuncionalismo - CNPq, Grupo Janus, sobre o uso do Português Brasileiro e, em específico, sobre o vernáculo conquistense. Ademais, este trabalho teve como objetivo auxiliar na composição de um conjunto significativo de informações com o objetivo de caracterizar essa variedade do Português a partir de uma análise de vertente funcionalista, especialmente na sua interface com os estudos cognitivistas e está sujeito, sobretudo, a novas inquietações, constatações e, principalmente, refutações a fim de que o conhecimento acerca da língua(gem) seja o ponto de partida para entender a complexidade das estratégias linguísticas utilizadas pelos falantes nas suas relações interpessoais.

\section{Referências}

ARENA, A. B. Rota de construcionalização do conector daí que: uma abordagem funcional centrada no uso. SOLETRAS. Rio de Janeiro. n. 28, v. 2. 2014, p. 60-78.

BECHARA, Evanildo. Moderna Gramática Portuguesa. Rio de Janeiro: Lucerna, 2004.

BYBEE, J. Language, usage and cognition. Cambridge: Cambridge University Press, 2010.

CROFT, W. Radical construction grammar: syntactic theory in typological perspective. Oxford: Oxford University Press, 2001.

CUNHA LACERDA, P. F. A. O papel do método misto na análise de processos de mudança em uma abordagem construcional: reflexões e propostas. Revista Linguística. Rio de Janeiro. v. 12 , n. 1, 2016. p. 83-101.

.; OLIVEIRA, N. F. Abordagem construcionista na gramaticalização: perspectivas e contribuições. In: OLIVEIRA, M. R.; ROSÁRIO, I. C. (orgs.). Linguística centrada no uso: teoria e método. Rio de Janeiro: Lamparina/FAPERJ, 2015, p. 51-62. 
DAVIES, Mark; FERREIRA, Michael. Corpus do Português: 45 million words, 1300s1900s. (2006). Disponível em: http://www.corpusdoportugues.org/. Acesso em: 21 jul. 2018.

DIEWALD, Gabriele. Context types in grammaticalization as constructions. Constructions SV, 2006, p. 1-9.

FRIED, M. Construction Grammar. In: ALEXIADOU, A.; KISS T. (Eds.). Handbook of syntax. 2. ed. Berlin: Walter de Gruyter, 2015. p. 974-1003.

FURTADO DA CUNHA, M. A.; BISPO, E. B.; SILVA, J. R. Variação e mudança linguística em perspectiva construcional. Natal: EDUFRN, 2018.

GOLDBERG, A. Constructions: A Construction Grammar Approach to Argument Structure. Chicago: The University of Chicago Press, 1995.

HEINE, Bernd. On the role of context in grammaticalization. In: WISCHER, I. and DIEWALD, G. (eds.) New Reflections on Grammaticalization. 2002. xiv, 437 p. 83-101.

HIMMELMANN, N. P. Lexicalization and grammaticalization: Oppositive or orthogonal? In: BISANG, W. et al. (Ed.). What makes grammaticalization? Berlin: Mouton de Gruyter, 2004. p. 21-42.

LÔBO, C. M. G. N.; CASSEB-GALVÃO, V. C.; A mudança e constituição da microconstrução "pois não" no português brasileiro. Revista Linguística. Rio de Janeiro. v. 14, n.1, 2018. p. 251-282.

MATTOS E SILVA, Rosa Virgínia. O Português Arcaico: fonologia, morfologia e sintaxe. São Paulo: Contexto, 2006.

OLIVEIRA, M. R. de. Contexto: definições e fatores de análise. ; ROSÁRIO, I. da C. do. (orgs.). Linguística centrada no uso: teoria e método. Rio de Janeiro: Lamparina/FAPERJ, 2015, p. 22-35.

- O afixoide lá em construções do Português: perspectivização espacial e

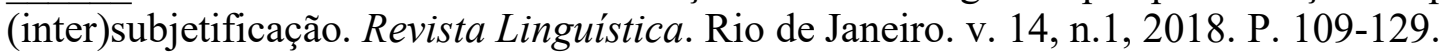

ROSARIO, I. C.; OLIVEIRA, M. R. Funcionalismo e abordagem construcional da gramática. Alfa: Revista de Linguística (UNESP. Online), v. 60, p. 233-259, 2016.

TEIXEIRA, A. C. M; ROSÁRIO, I. C. O estatuto da microconstrucionalização no quadro da mudança linguística. Revista Linguística. Revista do Programa de Pós-Graduação em Linguística da Universidade Federal do Rio de Janeiro. Volume Especial, dez de 2016, p. 139-151.

TRAUGOTT, E. C.; TROUSDALE, G. Constructionalization and constructional changes. Oxford: Oxford University Press, 2013. 


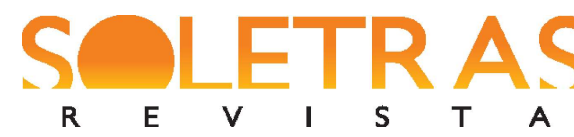

N.37 - 2019.1 - CAIO AGUIAR VIEIRA

VALÉRIA VIANA SOUSA

Press, 2005.

; DASHER, R. Regularity in semantic change. Cambridge: Cambridge University

\title{
The constructional architecture of the que nem in the Portuguese Language: constructionalization and constructional changes
}

\begin{abstract}
In this paper, we investigate the constructional changes and the constructionalization of the que nem used in the Portuguese Language as a comparative connector, under the bias of the UsageBased Model. Therefore, based on a qualitative-quantitative analysis, we aim, through the diachronic prism, to trace the route of the form-meaning pairing in the "que nem" in Portuguese in perspective of the context types proposed by Diewald (2006). From a synchronic point of view, we analyze, under the bias of the constructional perspective of change (BYBEE, 2010; TRAUGOTT; TROUSDALE, 2013; ROSÁRIO; OLIVEIRA, 2016; FURTADO DA CUNHA; BISPO; SILVA, 2018) the que nem form-meaning pairing and the sanction of new nodes in the linguistic network based on Corpora Popular and Culto de Vitória da Conquista - BA - Corpora PCVC and PPVC. The results of the research showed that a new node was formed in the Portuguese language with a comparative formalmeaning configuration. In addition, we found a reduction in the "que nem" compositionality, an increase in schematicity and productivity, thus evidencing the host-class expansion (HIMMELMANN, 2004), since new subschemases were activated in the network, performing the formal-meaning configuration of comparison, exemplification and conformity, allied to a growing continuum of subjectivity.
\end{abstract}

Keywords: Que nem. Constructionalization. Usage-Based Model.

Recebido em: 04 de novembro de 2018.

Aceito em: 23 de março de 2019. 